\title{
Extraneural Supratentorial Primitive Neuroectodermal Tumor Metastasis: An Adult Case Report
}

\author{
Nidhal Matar ${ }^{1}$ Kamel Bahri ${ }^{1} \quad$ Jallel Kallel ${ }^{1} \quad$ Adnene Boubaker $^{1} \quad$ Hafedh Jemel $^{1}$ \\ ${ }^{1}$ Department of Neurological Surgery, Institut National de \\ Neurologie, University el Manar, Faculté de Medicine de Tunis, \\ Tunisie \\ Address for correspondence Nidhal Matar, MD, Institut National de \\ Neurologie, Tunis, Tunisia (e-mail: matarnidhal2007@yahoo.fr). \\ Indian J Neurosurg 2017;6:210-212.
}
Abstract
Keywords
- supratentorial
- primitive neuroectodermal tumor
- extracranial
- metastases

Extraneural metastases of supratentorial primitive neuroectodermal tumors (PNET) are very rare and have been reported in only sporadic cases. We present a patient with supratentorial PNET metastasizing to the lung, diagnosed 4 months after cerebral surgery.

\section{Introduction}

Primitive neuroectodermal tumor (PNET) is an undifferentiated neoplasm arising from the germinal matrix of the primitive neural tube. It is predominantly an infratentorial tumor of childhood. Adult supratentorial PNETs are less common and extraneural metastasis are extremely unusual. Only five sporadic cases were reported in the international literature. ${ }^{1-6}$ In this article, we report a rare case of a young woman who had supratentorial PNET with extracranial metastases involving the lung.

\section{Case Report}

A 32-year-old woman with a 1-month history of headache, nausea, and vomiting was admitted to hospital. Neurologic examination revealed left hemiparesis and bilateral papilledema. Magnetic resonance imaging (MRI) studies revealed a huge mass with an irregular margin in the right parietal region, which enhanced partially after gadolinium administration (-Fig. 1). Chest X-ray showed no abnormality.

received

April 10, 2015

accepted after revision

April 4, 2016

published online

June 9, 2017
DOI https://doi.org/

$10.1055 / \mathrm{s}-0036-1584597$. ISSN 2277-954X.
A right parietal craniotomy was performed. After cordectomy, we found a dark, well-demarcated, friable, and highly vascularized tumor. It was totally removed.

Histopathological examination showed neoplastic tissue: The tumor was composed of diffuse sheets and clusters surrounded by fibroreticular septa. We also found small cells with a rounded nucleus and a chromatin arranged in big lump. The gross and microscopic morphology of the tissue and the results of the immunocytochemical analysis were consistent with the diagnosis of PNET.

After surgery, we treated the brain with $64 \mathrm{~Gy}$ dose of radiation. After 4 months, the patient presented in a poor general condition. She had progressive dyspnea, hemoptysis, and left thoracic pain. There were no neurologic abnormalities.

Chest X-ray revealed voluminous left thoracic masse (-Fig. 2). Cerebral MRI showed no recurrence, and the tomography study of the abdomen and pelvis showed no other tumor localization. Bronchopulmonary fibroscopy was performed and biopsy concluded to a PNET metastasis. With this diagnosis, we initiated a chemotherapy regimen for 6 months (six cycles). The patient was still under treatment at the time of the writing of this article.

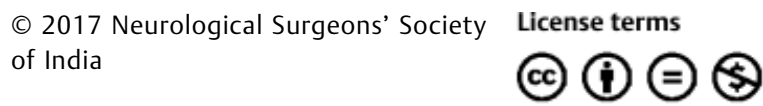



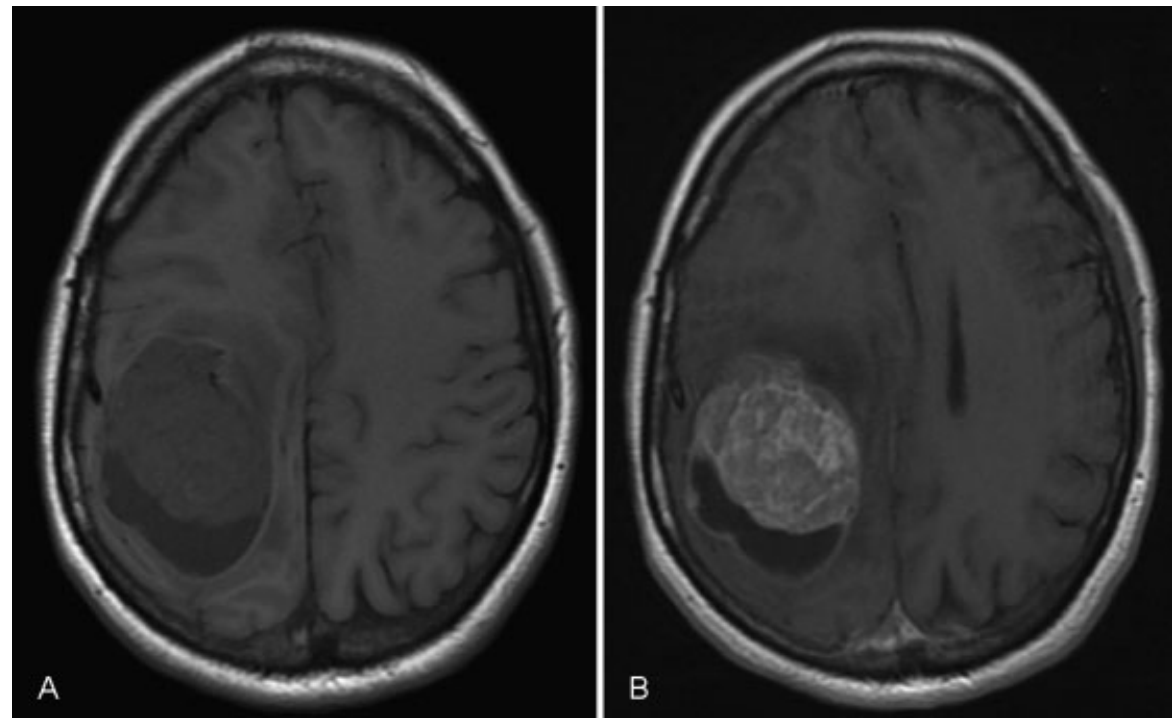

Fig. 1 T1-weighted axial MRIs. (A) A mass in the right parietal lobe with heterogeneous signal suggesting intratumoral cyst. (B) Gadolinium produces inhomogeneous enhancement.

\section{Discussion}

According to the World health Organization, supratentorial primitive neuroectodermal tumor is defined as a cerebellar or suprasellar embryonal tumor made up of undifferentiated or poorly differentiated neuroepithelial cells, which have the capacity of displaying divergent differentiation along neuronal, astrocytic, ependymal, muscular, or melanocytic lines. Precise incidence is difficult to determine because of controversies regarding the classification of these tumors and their rarity. They approximately accounted for $2.8 \%$ of all primary cerebral

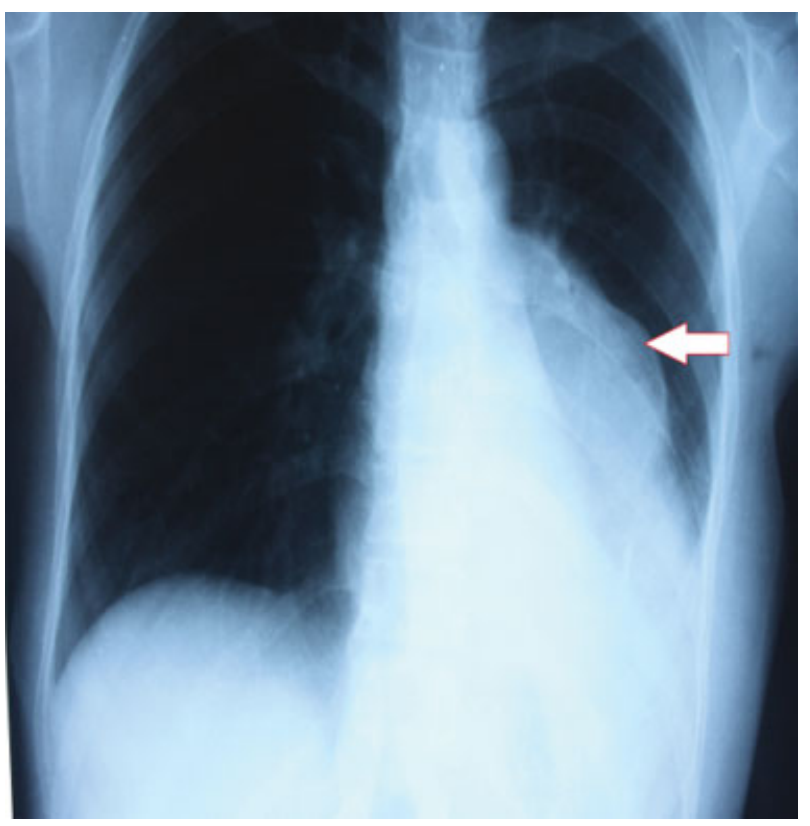

Fig. 2 Chest radiography: voluminous left thoracic masse (arrow). tumors with only $5.6 \%$ supratentorial. They usually occur in children and sporadically in adults.

Multiform glioblastoma and medulloblastoma are the main providers of extracranial metastases. Smith et $\mathrm{al}^{7}$ found a $0.44 \%$ incidence of extracranial metastases of multiform glioblastoma among 8,000 primary brain tumors included in their study, making it the most supratentorial entity that gives rise to extraneural metastases. In a review of the literature, we found only six reports of supratentorial PNETs with extraneural metastases (-Table $\mathbf{1}$ ). In two cases, tumors were cerebral neuroblastoma. ${ }^{2,4}$

Many reasons can explain this rarity. First, the cerebrum does not have a lymphatic system. Second, intracerebral veins are thin-walled and would probably collapse early from compression by an expanding tumor. Furthermore, the immunologic response of the host organ to tumor cells may prevent their growth outside the central nervous system (CNS). ${ }^{7,8}$ Finally, the life span of patients with intracranial tumors tends to be short. 5,7

However, metastases frequently occur in patients who have been treated with cranial surgery, which suggests that local mechanical barriers are more important than the inability of the tumors to survive in a new environment. ${ }^{9-11}$ The nature of this barrier is still unknown. Perhaps a more likely explanation is that craniotomy enables the vascular channels to be opened and also the spreading of tumoral cells in the extracranial soft tissue and to gain access to the extracranial blood and lymph vessels. ${ }^{6,9}$ Even so, Takeuchi and Handa ${ }^{4}$ report a case of cerebral neuroblastoma metastasizing in nodes without surgery.

By far, sites of those extraneural metastases were regional lymph nodes. ${ }^{2-6}$ Nevertheless, Han et al ${ }^{1}$ report a case that PNET metastasis occurs in the lung and multiple vertebral bodies. In the present case also the site of metastasis occurs in the lung. 
212 Extraneural Supratentorial PNET Metastasis Matar et al.

Table 1 Literature review of cases reporting extraneural metastases from supratentorial PNETs

\begin{tabular}{|l|l|l|l|}
\hline Authors & Years & Histology & Sites of metastases \\
\hline Richard et $\mathrm{al}^{3}$ & 1967 & Medulloepithelioma & Skin-nodes \\
\hline Henriquez et $\mathrm{al}^{2}$ & 1973 & Neuroblastoma & Nodes \\
\hline Takeuchi and Handa 4 & 1979 & Neuroblastoma & Nodes \\
\hline Yu et $\mathrm{al}^{6}$ & 1990 & PNET & Nodes \\
\hline Han et al $^{1}$ & 2006 & PNET & Vertebral bone-lung \\
\hline Terheggen et $\mathrm{al}^{5}$ & 2007 & PNET & Nodes \\
\hline Our case & 2013 & PNET & Lung \\
\hline
\end{tabular}

Abbreviation: PNET, primitive neuroectodermal tumor.

\section{Conclusion}

Extraneural metastases from supratentorial PNETs have rarely been reported. We found only six cases in the international literature. We present a rare case of supratentorial PNET occurring in adult, which metastasized in the lung.

\section{References}

1 Han SR, Sohn MJ, Yoon SW, et al. Extracranial metastases of a supratentorial primitive neuroectodermal tumour. J Clin Neurosci 2007; 14(1):55-58

2 Henriquez AS, Robertson DM, Marshall WJ. Primary neuroblastoma of the central nervous system with spontaneous extracranial metastases. Case report. J Neurosurg 1973;38(2):226-231

3 Van Epps RR, Samuelson DR, McCormick WF. Cerebral medulloepithelioma. Case report. J Neurosurg 1967;27(6):568-573

4 Takeuchi J, Handa H. Spontaneous extracranial metastasis of cerebral neuroblastoma. Surg Neurol 1979;12(4):337-339

5 Terheggen F, Troost D, Majoie CB, Leenstra S, Richel DJ. Local recurrence and distant metastasis of supratentorial primitive neuro-ectodermal tumor in an adult patient successfully treated with intensive induction chemotherapy and maintenance temozolomide. J Neurooncol 2007;82(1):113-116

6 Yu IT, Ho DM, Wong TT, Liu HC. Congenital cerebral primitive neuroectodermal tumor with astrocytic differentiation and extracranial metastases. Childs Nerv Syst 1990;6(3): 179-182

7 Smith DR, Hardman JM, Earle KM. Metastasizing neuroectodermal tumors of the central nervous system. J Neurosurg 1969;31(1): 50-58

8 Utsuki S, Tanaka S, Oka H, Iwamoto K, Sagiuchi T, Fujii K. Glioblastoma multiforme metastasis to the axis. Case report. J Neurosurg 2005;102(3):540-542

9 Gyepes MT, D’angio GJ. Extracranial metastases from central nervous system tumors in children and adolescents. Radiology 1966;87(1):55-63

10 Jacobs JJ, Rosenberg AE. Extracranial skeletal metastasis from a pinealoblastoma. A case report and review of the literature. Clin Orthop Relat Res 1989;(247):256-260

11 Makeever LC, King JD. Medulloblastoma with extracranial metastasis through a ventriculovenous shunt. Report of a case and review of the literature. Am J Clin Pathol 1966;46(2): 245-249 